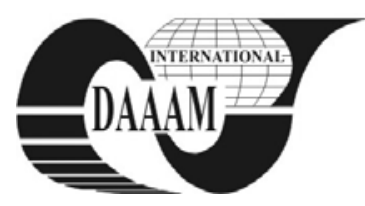

Annals of DAAAM for 2011 \& Proceedings of the 22nd International DAAAM Symposium, Volume 22, No. 1, ISSN 1726-9679 ISBN 978-3-901509-83-4, Editor B. Katalinic, Published by DAAAM International, Vienna, Austria, EU, 2011 Make Harmony between Technology and Nature, and Your Mind will Fly Free as a Bird Annals \& Proceedings of DAAAM International 2011

\title{
OLAP SOLUTION FOR SUPPLY CHAIN RISK MANAGEMENT
}

\author{
ZOUZELKOVA, I[veta]
}

\begin{abstract}
OLAP is a multidimensional technology offering a complex view on aggregated data. Qualities of this technology can be successfully used in Supply Chain Risk Management (SCRM). OLAP seems to be suitable for this kind of application because it shows data according to time, a process and a level of company hierarchy. These data can support strategic decision-making of storage managers as well as company top management. The primary focus of this paper is on advantages and disadvantages of OLAP used in SCRM. It discusses different risk factors, mentions integration of OLAP in Enterprise Resource Planning (ERP) software and deals with interconnection between different data sources and OLAP.
\end{abstract}

Key words: supply chain risk management, OLAP, risk factors, data mining

\section{INTRODUCTION}

In these days competitiveness of a company depends on many influences. A supply chain, one of the most important parts of every firm, can be endangered by many external or internal factors. Finding these possible risks and managing them is the main goal of SCRM as an essential part of Supply Chain Management (SCM).

On-Line Analytical Processing (OLAP) is a multidimensional technology usually used to analyze aggregated data from different points of view. OLAP became a key tool in Business Intelligence. The possibility of using OLAP technology in Risk Management has become an important aspect.

The increasing interest in effective company management is being solved by ERP software. These applications are mainly prepared for control and signal function.

Many recent studies have focused on integrating knowledge management into SCM. The need of OLAP as a part of flexible and efficient SCM is obvious. Classical ERP systems were not able to solve multidimensional tasks on different levels of company infrastructure and in a different time range. Operative SCM system needed data from OLAP as well as from ERP (Pátek, 2001). This study was focused on SCM as a whole and did not mention the usage of OLAP in Risk Management. Knowledge management and data mining for SCRM were the topics of other study published by Bing-hua \& Guo-fang (2009). OLAP was only mentioned as a useful tool for SCRM.

As mentioned above this topic does not belong to much discussed ones. As a matter of this fact, a research focused on this specific issue was designed.

\section{SUPPLY CHAIN MANAGEMENT RISKS}

Risks influence smooth work of a supply chain. They can be easily identified, anticipated and controlled. A successful fight against risks depends on creation of a supply chain resistant to chaos. Risk Management became an essential part of SCM and managers had to get used to evaluating risks in every single day (Kinder, 2009).

\subsection{Environmental Risk Factors}

There are several factors that can cause risks. Firstly, environmental influences should be mentioned. The supply chain is a part of macroeconomist, sociocultural, governmental and natural surroundings. For example a meteorological phenomenon, labor demonstrations, new market opportunities, raw materials availability, government actions, fiscal and monetary reforms, political stability and other factors can affect supply chain performance. These are results of third party activities and can be hardly controlled (Kara et al., 2008). On the other hand, these sources of risks do not always mean a problem. They can have also positive effect on business. However, especially these factors are perceived by managers as the most redoubtable (Kinder, 2009).

\subsection{Supply Chain Related Risk Factors}

The risk areas that can be influenced can be seen in supply chain related factors such as delivery, demand, information systems, supply, production planning, strategy, human resources and other relations (Kara et al., 2008). Concrete risks are specific to an individual firm and its business focus. Despite this fact there are general problems such as supplier failure, production interruption, logistic problems, IT failure, rising oil and energy prices that can be found in every branch.

\subsection{The Risk Management Cycle}

At the beginning of every risk preventing action is an identification of the potential risks. The chosen method can be influenced by culture, industry practice and compliance. The mostly used methods are Objective-based risk identification (finds events endangering objective achieving), Scenario-based risk identification (any event that triggers an undesired scenario alternative is identified as risk), Taxonomy-based risk identification (a questionnaire based risk reveal), Common-risk checking, Risk charting (a matrix of before mentioned approaches and risk factors) (Wikipedia, 2011).

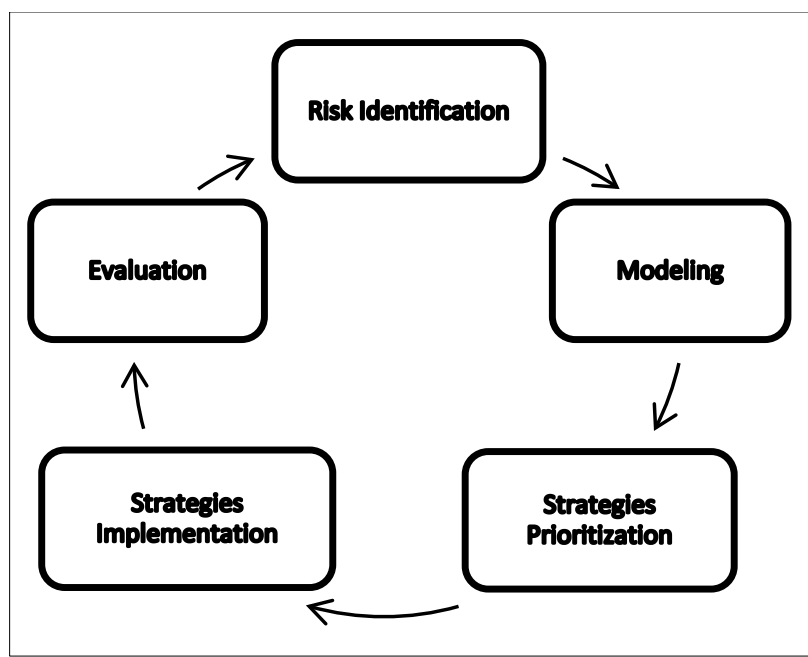

Fig. 1. The Risk Management cycle 
Logically, modeling and design of risk avoiding strategies are the next step. These strategies are usually focused on flexibility and efficiency. Flexibility of a supply chain is usually seen as more important than its efficiency. Organization with an extensive supply chain is able to react more flexible to principal changes such as rising transport costs and test different strategies (Kinder, 2009).

The third step usually includes an implementation process of the created strategies that should be evaluated by priorities and created for different levels of supply chain flow.

When a risk comes, the faster it is discovered the better reaction can be taken. In this case time is essential. The risk is handled according to the chosen strategy. Consequently, the used strategy is evaluated and revealed deficiencies are integrated. The whole cycle can be seen in Fig. 1 .

\section{OLAP TECHNOLOGY IN SCRM}

As mentioned before, OLAP technology became a standard part of ERP systems. But the usage of OLAP functions in these systems is very limited. Usually it focuses only on specific tasks connected with concrete implementation. This approach tends to be ineffective when the company grows and need for strategic decision-making increases.

\subsection{Requirements for OLAP}

The main advantage of the OLAP solution is the possibility of making analysis on different levels of a company hierarchy, of various processes and in an unequal time range. The multidimensional concept enables partial decision-making of every supply manager on his or her level. On the other hand, operational controlling can be limited, because data saved in OLAP are aggregated. The depth of the aggregation depends on a set hierarchy structure of dimension attributes.

The aggregation also influences performance. The larger cardinality of data is, the slower the OLAP engine can be. Furthermore, strategic decision-making requires a constant input of actual data. OLAP does not work as a classical relational database and data processing in real-time can be very demanding.

The SCRM system also requires warning mechanisms, which can highlight weak areas of a supply chain and reveal some potential risks. This kind of an indicator system is usually included in every ERP and there is not a reason for implementing OLAP (Pátek, 2001).

\subsection{OLAP Implementation}

The implementation of OLAP into SCM system can be realized by a separated warehouse, which is usually connected with production databases, ERP and other databases.

Fig. 2. reveals the connection of used components. It shows the whole process beginning with data acquisition from data storage. Common data source formats are relational databases, XML files, non-relational database structures such as Information Management Systems (IMS) and other DBMS.

Than Extract, Transform, Load (ETL) process follows. This procedure involves extracting data from different source systems. Each of them may use a different data organization. The goal of extraction phase is to convert the data into a single format, which is appropriate for transformation processing. The transformation includes data manipulation such as selecting certain columns, translating coded values, sorting, joining data from multiple sources, aggregating data and other simple or complex data validation.

Finally are the data loaded into the end target, usually the data warehouse (Wikipedia, 2011). ETL saved cleaned data into data warehouse where can be easily accessed by OLAP.

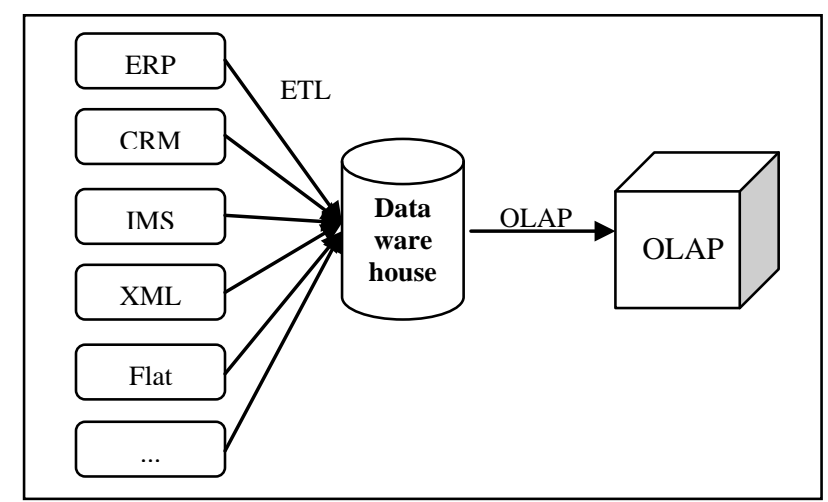

Fig. 2. OLAP implementation in SCRM

\section{CONCLUSION}

This report brings together supply chain risks that should be handled and solutions OLAP can offer. It also discusses demands on OLAP and benefits of its integration into SCRM. The main purpose of this study was to consider usage of OLAP in Risk Management.

OLAP implementation in SCM varies on a client by client basis and their business focus. It is hard to generalize that OLAP is always necessary in SCRM. Its importance grows according to a company size. It should be also noted that OLAP is not designed for making decisions itself. It can only display data in a proper form to support decision-making of an authorized manager. In fact, for forecasting and future estimation datamining could be more suitable than OLAP. But nowadays, many OLAP systems offer also datamining services.

This study stands at the begining of a more extensive analysis in this area. In general, OLAP revealed as a suitable tool for SCRM. However, this solution has some limitations. The next step will lead to comparison of existing SCM and their properties. In the future, new SCRM with implemented OLAP will be designed.

\section{ACKNOWLEDGEMENTS}

This survey was financed by Internal Grant Agency No. IGA/49/FAI/10/D, SV30111049020.

\section{REFERENCES}

Bing-hua, H. \& Guo-fang, S. (2009) Knowledge Management and Data Mining for Supply Chain Risk Management, Proceedings of International Conference on Engineering Management and Services EMS 2009, September 20-22, 2009, Beijing, China, ISBN: 978-1-4244-4639-1

Kara, S.; Kayis, B. \& Gomez, E. (2008). Managing Supply Chain Risks in Multi-site, Multi-partner Engineering Projects. Communications of the IBIMA, Vol. 5, No.1, pages 100-112, ISSN 1943-7765.

Kinder, A. (2009). Supply Chain Risk Management Minimizes Losses. System On Line, ISSN 1802-615X, Available from: http://www.systemonline.cz/clanky/rizeni-rizikdodavatelskeho-retezce-minimalizuje-ztraty.htm Accessed on: 2011-08-04

Pátek, M. (2001). OLAP as a part of Supply Chain Management. System On Line, ISSN 1802-615X, Available from:http://www.systemonline.cz/clanky/olap-jako-soucastsupply-chain-managementu.htm Accessed on: 2011-08-04

*** (2011) http://en.wikipedia.org/wiki/Risk_management Risk management, Wikipedia, Accessed on: 2011-08-05

*** (2011) http://en.wikipedia.org/wiki/Extract,_transform, _load - Extract, transform, load, Wikipedia, Accessed on: 2011-08-24 